\title{
High mobility group box 1 contributes to anti-neutrophil cytoplasmic antibody-induced neutrophils activation through receptor for advanced glycation end products (RAGE) and Toll-like receptor 4
}

\author{
Chen Wang, Huan Wang, Dong-Yuan Chang, Jian Hao, Ming-Hui Zhao and Min Chen ${ }^{*}$
}

\begin{abstract}
Introduction: High mobility group box-1 (HMGB1), a typical damage-associated molecular pattern (DAMP) protein, is associated with inflammatory conditions and tissue damage. Our recent study found that circulating HMGB1 levels could reflect the disease activity of antineutrophil cytoplasmic antibody (ANCA)-associated vasculitis (AAV). The current study aimed to investigate whether HMGB1 participated in ANCA-induced neutrophil activation, which is one of the most important pathogenic aspects in the development of AAV.
\end{abstract}

Methods: The various effects of HMGB1 in ANCA-induced neutrophil activation were measured. Antagonists for relevant receptors and signaling molecules were employed.

Results: ANCA antigens translocation on neutrophils primed with HMGB1 was significantly higher than non-primed neutrophils. The levels of respiratory burst and degranulation increased significantly in HMGB1-primed neutrophils activated with ANCA-positive lgG, as compared with non-primed neutrophils. Furthermore, blocking Toll-like receptor 4 (TLR4) and receptor for advanced glycation end products (RAGE), rather than TLR2, resulted in a significant decrease in HMGB1-induced ANCA antigens translocation, respiratory burst and degranulation. Similar effects were also found when blocking MyD88 and NF-KB.

Conclusions: HMGB1 could prime neutrophils by increasing ANCA antigens translocation, and the primed neutrophils could be further induced by ANCA, resulting in the respiratory burst and degranulation. This process is TLR4- and RAGE-dependent through the MyD88/NF-kB pathway.

\section{Introduction}

Antineutrophil cytoplasmic antibody (ANCA)-associated vasculitis (AAV) consists of granulomatosis with polyangiitis (GPA, previously named Wegener's granulomatosis), microscopic polyangiitis (MPA) and eosinophilic granulomatosis with polyangiits (EGPA) [1]. The serological markers for the aforementioned primary small vessel vasculitis were ANCAs, which recognize a variety of target antigens, in particular, proteinase 3 (PR3) and myeloperoxidase (MPO).

\footnotetext{
* Correspondence: chenmin74@sina.com

Department of Medicine, Renal Division, Peking University First Hospital; Institute of Nephrology, Peking University, Key Laboratory of Renal Disease, Ministry of Health of China, 8, Xishiku Street, Beijing 100034, China
}

ANCA-induced neutrophil activation is increasingly being recognized to play an important role in the pathogenesis of AAV. Cytokines or other proinflammatory mediator, such as C5a and tumor necrosis factor- $\alpha$ (TNF- $\alpha$ ), could prime neutrophils by inducing more ANCA antigens expression on the surface of neutrophils. Thus, ANCAs could further activate primed neutrophils to undergo a respiratory burst and degranulation, which plays a direct pathogenic role in the development of vasculitis [2-6]. Furthermore, it was demonstrated that in animal studies that ANCA and neutrophils were necessary for the pathogenesis of AAV $[7,8]$. 
High mobility group box-1 (HMGB1) exists within the nucleus ubiquitously, playing its nuclear role by stabilizing the structure of nucleosomes and inducing DNA bending [9]. In recent years, a novel role of HMGB1 as a typical damage-associated molecular pattern (DAMP) protein when placed extracellularly has been attracting increasing attention [10]. The signal pathways of HMGB1 involve a number of signaling molecules and receptors, including receptor for advanced glycation end products (RAGE) and Toll-like receptors (TLR) 2 and 4, may participate in HMGB1 signaling [11-13].

In our recent study, we observed circulating HMGB1 levels are closely associated the disease activity of AAV [14]. Therefore, it is reasonable to further investigate whether HMGB1, a proinflammatory mediator, plays a pathogenic role in the development of AAV. It is noticed that HMGB1 has a variety of effects on neutrophils, which are the most important effector cells in the pathogenesis of AAV. Fan et al. reported that HMGB1/TLR4 signaling attributed to the activation of neutrophils NADPH oxidase, which further induced neutrophil-mediated inflammation and organ injury after hemorrhage [15]. In vitro, HMGB1 played an essential regulatory role in neutrophil recruitment and migration to inflammatory tissues [16]. Therefore, we hypothesized that the HMGB1 participates in ANCA-induced neutrophil activation. Furthermore, in the current study, we also investigated receptors and intracellular signaling pathways involved in HMGB1primed neutrophils for ANCA-induced activation.

\section{Materials and methods Reagents}

Recombinant HMGB1 proteins were purchased from $\mathrm{R} \& \mathrm{D}$ Systems (C23-C45 disulfide C106 thiol form) (Abingdon, UK). The endotoxin level of HMGB1 was below the detection limit $(0.125 \mathrm{EU} / \mathrm{mL})$ of the Limulus assay (Sigma-Aldrich, St Louis, MO, USA). Recent studies found the functionality of HMGB1 is affected by the redox state of its three cysteine residues (C23, C45 and C106). The intramolecular disulfide bond between Cys23 and Cys45 as well as the presence of the unpaired Cys106 thiol were critical for HMGB1-induced proinflammatory activity $[17,18]$. The recombinant HMGB1 used in our study has been adjusted to the above form to ensure proinflammatory activity.

Antibodies blocking the TLR2 and TLR4 were purchased from eBioscience (San Diego, CA, USA). RAGE-Fc was purchased from R\&D Systems (Minneapolis, MN, USA). Inhibitor of myeloid differentiation factor 88 (MyD88) was purchased from Imgenex (San Diego, CA, USA), while inhibitor of nuclear factor kappa B (NF-kB) (Bay11-7082) was from Biovision (Mountain View, CA, USA). For flow cytometry analysis, rabbit polyclonal antibody against human PR3 was purchased from Abcam
(Cambridge, UK), with addition of irrelevant IgG control antibody and phycoerythrin (PE)-conjugated goat antirabbit antibody. Fluorochrome dihydrorhodamine was purchased from Sigma-Aldrich (St Louis, MO, USA). For Western blot analysis, antibodies against MyD88 (D80F5) and NF-кB p65 (Ser536) were purchased from Cell Signaling Technology (Beverly, MA, USA).

\section{Preparation of $\lg \mathrm{G}$}

Normal immunoglobulin G (IgG) and ANCA-positive IgG were prepared from plasma of normal volunteers and patients with active PR3-ANCA- or MPO-ANCApositive primary small vessel vasculitis, using a HighTrap-protein G column on an AKTA-FPLC system (GE Biosciences, South San Francisco, CA, USA). None of these patients had dual positivity of PR3-ANCA and MPO-ANCA. Preparation of IgG was performed according to the methods described previously $[19,20]$. We obtained written informed consent from all participants involved in our study. The research was in compliance of the Declaration of Helsinki and approved by the clinical research ethics committee of the Peking University First Hospital.

\section{Neutrophil isolation}

Neutrophils were isolated from heparinized venous blood of healthy donors by density gradient centrifugation on PolymorphPrep (Nycomed, Oslo, Norway). Then neutrophils were washed in Hank's balanced salt solution without $\mathrm{Ca}^{2+} / \mathrm{Mg}^{2+}$ (HBSS-/-; Chemical Reagents, Beijing, China) and suspended in HBSS with $\mathrm{Ca}^{2+} / \mathrm{Mg}^{2+}$ (HBSS+/+; Chemical Reagents, Beijing, China) to a concentration of $1 \times 10^{6}$ cells/ml and used for further analysis.

\section{Cytotoxicity assay}

The effect of various blocking antibodies and inhibitors on cell toxicity was determined by measuring the secretion of lactate dehydrogenase (LDH) using the Cytotoxicity Detection Kit (Roche Diagnostics, Mannheim, Germany) according to manufacturer's recommendation.

\section{Membrane expression of PR3 (mPR3) on neutrophils after priming}

Flow cytometry was used to evaluate PR3 expression on neutrophils. Neutrophils were incubated with a concentration of HMGB1 at $10 \mathrm{ng} / \mathrm{ml}$, which was comparable to the circulating HMGB1 level in active AAV patients, as demonstrated in our previous study [14] or buffer control, for $30 \mathrm{~min}$ at $37^{\circ} \mathrm{C}$. The time was set according to the result of our finding that the $\mathrm{mPR} 3$ expression increased gradually over time within $30 \mathrm{~min}$. To avoid influence on the activity and survival of cells with longer time, the priming time was set to 30 min (Figure 1A). In order to investigate the role of candidate receptors and 

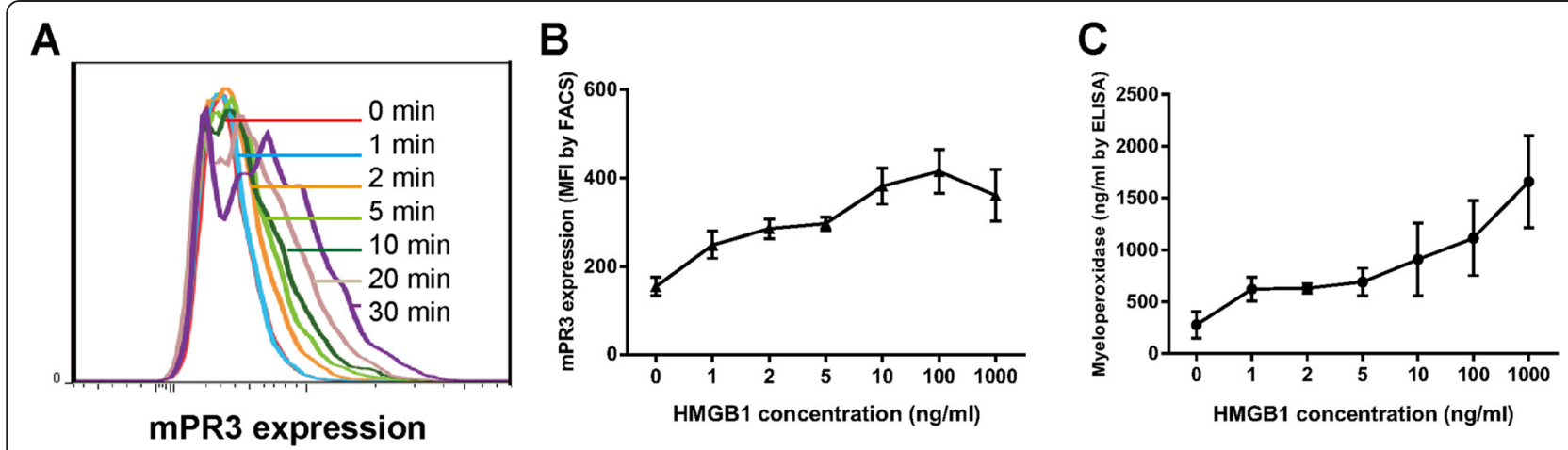

Figure 1 Dose-response curve for HMGB1 in priming neutrophils and a representative histogram of effects of HMGB1 on translocation of PR3 over time. (A) was a representative histogram of effects of HMGB1 on translocation of PR3 over time. The levels of mPR3 expression on neutrophils (B) and MPO in the supernatant of neutrophils (C) was roughly dose-dependent. Bars represent mean \pm standard deviation (SD) of repeated measurements of three independent experiments. HMGB1, high mobility group box-1; MPO, myeloperoxidase; PR3, proteinase 3.

signaling molecules in HMGB1-primed neutrophils, neutrophils were first incubated with blocking antibodies and inhibitors (anti-TLR2 at $5 \mu \mathrm{g} / \mathrm{ml}$; anti-TLR4 at $5 \mu \mathrm{g} / \mathrm{ml}$; RAGE-Fc at $5 \mu \mathrm{M}$; MyD88 inhibitor at $20 \mu \mathrm{M}$; NF- $\kappa \mathrm{B}$ inhibitor at $20 \mu \mathrm{M}$, the above inhibiting concentrations were set according to dose-dependent curve (Figure 2B-F) or buffer control for $1 \mathrm{~h}$ on ice. Neutrophils were incubated with $0.5 \mathrm{mg} / \mathrm{ml}$ heat-aggregated goat IgG for $15 \mathrm{~min}$ to saturate Fcy receptors. Next, cells were stained with a saturating dose of rabbit polyclonal antibody against human PR3 or with an irrelevant IgG control antibody for $30 \mathrm{~min}$ on ice. Neutrophils were then incubated with PEconjugated goat anti-rabbit antibody. All further steps were performed on ice and washing steps were carried out using HBSS $+/+$ containing $1 \%$ bovine serum albumin (BSA). Prepared neutrophils were analyzed using a FACScan (Becton Dickinson, Heidelberg, Germany) as described previously [21]. Cells allocated like neutrophils were gated in forward/sideward scatter (FSC/SSC) and data were collected from 10,000 cells per sample.

\section{Detection of MPO in the supernatant of HMGB1-primed neutrophils by ELISA}

MPO in the supernatant of HMGB1-primed neutrophils was tested by enzyme-linked immunosorbent assay (ELISA) using a commercial kit (USCNK, Wuhan, China). Cells were incubated with HMGB1 $(10 \mathrm{ng} / \mathrm{ml})$ for $30 \mathrm{~min}$ at $37^{\circ} \mathrm{C}$. Supernatant fluids were collected and used for ELISA analysis. Assay of role of candidate receptors and signaling molecules was described as above. The ELISA procedure of measuring MPO was as described previously [22].

\section{Measurement of respiratory burst by oxidation of dihydrorhodamine to rhodamine}

We assessed the generation of reactive oxygen radicals using dihydrorhodamine, as described previously [23]. In brief, isolated neutrophils were gradually warmed to $37^{\circ} \mathrm{C}$ and incubated with $0.05 \mathrm{mM}$ dihydrorhodamine for $10 \mathrm{~min}$ at $37^{\circ} \mathrm{C}$. Sodium azide $\left(\mathrm{NaN}_{3}\right)(2 \mathrm{mM})$ was added in order to prevent intracellular breakdown of $\mathrm{H}_{2} \mathrm{O}_{2}$ by catalase. Then, neutrophils were primed with $10 \mathrm{ng} / \mathrm{ml}$ HMGB1 for $30 \mathrm{~min}$ at $37^{\circ} \mathrm{C}$ and incubated with patientderived ANCA-positive-IgG $(300 \mu \mathrm{g} / \mathrm{ml})$ or normal IgGs $(300 \mu \mathrm{g} / \mathrm{ml})$ for $1 \mathrm{~h}$ at $37^{\circ} \mathrm{C}$. For assay of role of candidate receptors and signaling molecules, certain groups of neutrophils were pre-incubated with relevant reagents for $1 \mathrm{~h}$ on ice before the priming. The reaction was stopped by addition of $1 \mathrm{ml}$ of ice-cold HBSS/1\% BSA. Samples were kept on ice and analyzed using a FACScan. Cells allocated like neutrophils were gated in forward/sideward scatter (FSC/SSC) and data were collected from 10,000 cells per sample. The shift of green fluorescence in the FL-1 mode was determined. For each condition, the mean fluorescence intensity (MFI) (representing the amount of generated reactive oxygen radicals) was reported [21,24].

\section{ANCAs activated HMGB1-primed neutrophils degranulation}

Lactoferrin, an iron-binding multifunctional glycoprotein that was an abundant component of the specific granules of neutrophils [25], was considered as a biomarker of neutrophil degranulation [26]. Neutrophils were stimulated with HMGB1 $10 \mathrm{ng} / \mathrm{ml}$ or buffer for $30 \mathrm{~min}$ followed by stimulation with MPO-ANCA-positive IgG or PR3-ANCA-positive IgG, or normal IgGs for $1 \mathrm{~h}$, respectively. For assay of role of candidate receptors and signaling molecules, certain groups of neutrophils were pre-incubated with relevant reagents for $1 \mathrm{~h}$ on ice before the priming. Supernatant fluids were collected and used for ELISA analysis. Lactoferrin in the neutrophils supernatant were tested by ELISA using a commercial kit according to the manufacturer's instruction (USCNK, Wuhan, China). 


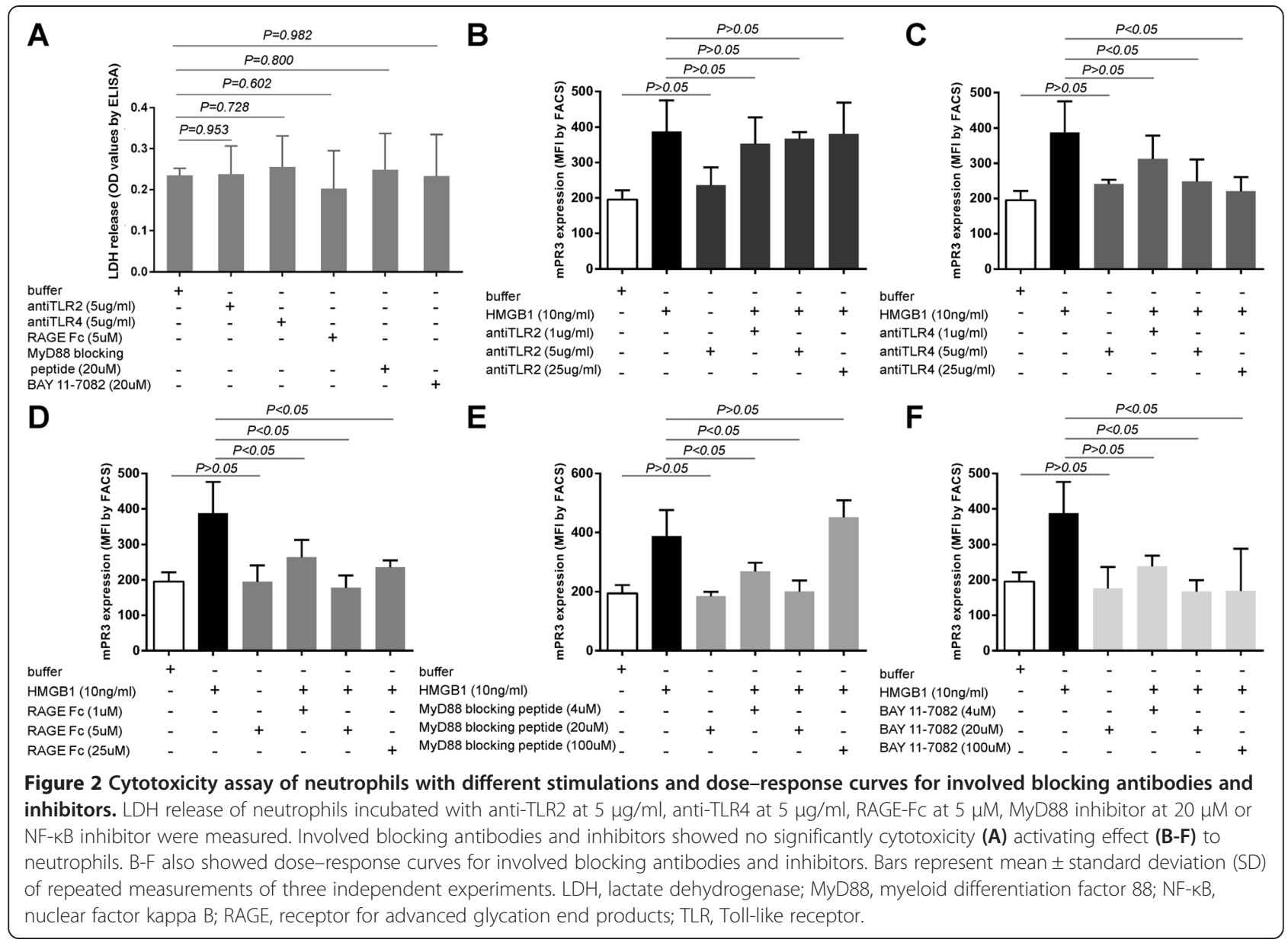

Western blot analysis of MyD88 and phospho-NF-KB

MyD88 is the common adaptor for almost all TLRs, and RAGE as well. The receptors associate with MyD88 through their TIR domains, recruiting serine/threonine kinases interleukin-1 receptor-associated kinases (IRAKs) to stimulate the TNF receptor-associated factor 6/IkB kinase (TRAF6/IKK) complex and mitogen-activated protein kinase-kinase (MAPKK), which result in activation of NF$\kappa B[27,28]$. Here MyD88 and NF- $\mathrm{B}$ were taken into investigation.

Neutrophils were stimulated with HMGB1 $10 \mathrm{ng} / \mathrm{ml}$ or buffer for 30 min followed by stimulation with MPOANCA-positive IgG or PR3-ANCA-positive IgG, normal IgG or buffer control for $1 \mathrm{~h}$, respectively. Samples were harvested and cell lysates were prepared using the NEPER Nuclear and Cytoplasmic Extraction Kit (Pierce, Rockford, IL, USA). The concentrations of samples were determined using a BCA protein assay kit (Sigma-Aldrich, Poole, UK). Samples were incubated for $5 \mathrm{~min}$ at $95^{\circ} \mathrm{C}$ in loading buffer and $30 \mu \mathrm{g}$ of protein per lane were loaded on $10 \%$ sodium dodecyl sulfate-polyacrylamide gel, electrophoresed, and blotted onto nitrocellulose membrane by semidry equipment. Membrane was blocked in 5\% BSA/ 0.05\% Tween 20/Tris-buffered saline (TBST) $1 \mathrm{~h}$ at room temperature. The target bands were detected using specific monoclonal rabbit antibodies against MyD88 and phospho-NF- $\kappa$ B p65 (1:1,000 dilution in 5\%BSA/TBST with a final concentration of $1 \mu \mathrm{g} / \mathrm{ml}$ ) or mouse antibody against GAPDH (1:500 dilution in 5\% BSA/TBST with a final concentration of $1 \mu \mathrm{g} / \mathrm{ml}$ ). The nitrocellulose membrane was incubated overnight at $4^{\circ} \mathrm{C}$ with gentle agitation, followed by three washes with TBST for $10 \mathrm{~min}$ each time. The strips were then incubated with peroxidaseconjugated affinity-purified goat anti-mouse IgG or goat anti-rabbit IgG (Sigma-Aldrich, St Louis, MO, USA) diluted at 1:10,000 with TBST/5\% BSA for $1 \mathrm{~h}$ at room temperature with gentle agitation. Finally, they were revealed on autoradiographic film using ECL Plus Western Blotting Detection System (GE Healthcare, Piscataway, NJ, USA).

\section{Statistical analysis}

Quantitative data were expressed as means \pm standard deviation (SD) (for data that were normally distributed) 
or median and quartiles (for data that were not normally distributed) as appropriated. Differences of quantitative parameters between groups were assessed using one-way analysis of variance (ANOVA) analysis (for data that were normally distributed) or Mann-Whitney $U$ test (for data that were not normally distributed) as appropriate. Differences were considered significant when $P<0.05$. Analysis was performed with SPSS statistical software package (version 13.0, SPSS Inc., Chicago, IL, USA).

\section{Results}

The effect of HMGB1 on neutrophils was dose-dependent First, neutrophils were incubated with various concentrations of $\operatorname{HMGB1}(1,2,5,10,100$ and $1000 \mathrm{ng} / \mathrm{ml})$, and mPR3 expression was determined by flow cytometry. The level of mPR3 expression on neutrophils was roughly dosedependent (Figure 1B). Then MPO in the supernatant of neutrophils primed by these concentrations of HMGB1 was then tested. The level of MPO in the supernatant of neutrophils was also dose-dependent (Figure 1C).

HMGB1 increased the expression of MPR3 on neutrophils and the concentration of MPO in the supernatant of neutrophils

Expression of mPR3 on neutrophils and the concentration of MPO in the supernatant of HMGB1-primed neutrophils of eight healthy donors were analyzed. Compared with non-primed neutrophils, the level of mPR3 expression was significantly higher on neutrophils primed with HMGB1 at concentration of $10 \mathrm{ng} / \mathrm{ml}(154.45 \pm 60.55$ vs. $274.71 \pm 158.93, P=0.023$ ) (Figure $3 \mathrm{~A}$ ). Similarly, compared with non-primed neutrophils, the concentration of MPO was significantly higher in the supernatant of neutrophils primed with HMGB1 at concentration of $10 \mathrm{ng} /$ $\mathrm{ml}(605.95 \pm 183.86 \mathrm{ng} / \mathrm{ml}$ vs. $1,576.05 \pm 878.55 \mathrm{ng} / \mathrm{ml}$, $P<0.001$ ) (Figure $3 \mathrm{C}$ ).
To exclude the influence of potentially contaminating platelet, we used three kinds of tubes containing different anticoagulant, that is, sodium citrate, EDTA and heparin, respectively, to collect blood and repeat our experiments. We found that the platelet contamination rates in neutrophils isolated from blood in EDTA tube and heparin tube were below $2 \%$, which is generally considered to be acceptable [29]. Furthermore, we stimulated neutrophils isolated from each anticoagulant tube with HMGB1 at $10 \mathrm{ng} / \mathrm{ml}$, and found no significant difference on mPR3 expression on these neutrophils (see Additional file 1 and Figure S1 in Additional file 2).

\section{ANCA induced HMGB1-primed neutrophils to respiratory burst and degranulation}

We studied whether HMGB1 primed neutrophils for ANCA-induced respiratory burst. ANCA-IgG were prepared from two patients with active PR3-ANCA-positive vasculitis, two patients with active MPO-ANCA-positive vasculitis and two healthy volunteers, respectively. Neutrophils of the above-mentioned eight healthy donors were analyzed. Compared with non-primed neutrophils, the MFI value increased significantly in HMGB1-primed neutrophils activated with PR3-ANCA-positive IgG or MPO-ANCA-positive IgG (229.39 \pm 43.56 vs. $343.92 \pm$ $59.35, P=0.001 ; 227.55 \pm 48.44$ vs. $312.89 \pm 90.15, P=$ 0.048 , respectively) (Figure $4 \mathrm{~A}$ and $\mathrm{B}$ ). No obvious respiratory burst activity was observed with HMGB1, ANCA-IgG alone, normal IgG alone or HMGB1 plus normal IgG, either.

Degranulation was determined by measuring the lactoferrin concentration in the supernatant of neutrophils stimulated by HMGB1 plus ANCA-positive IgGs. Compared with unstimulated neutrophils, the lactoferrin concentration increased significantly in the supernatant of HMGB1-primed neutrophils further induced by PR3-
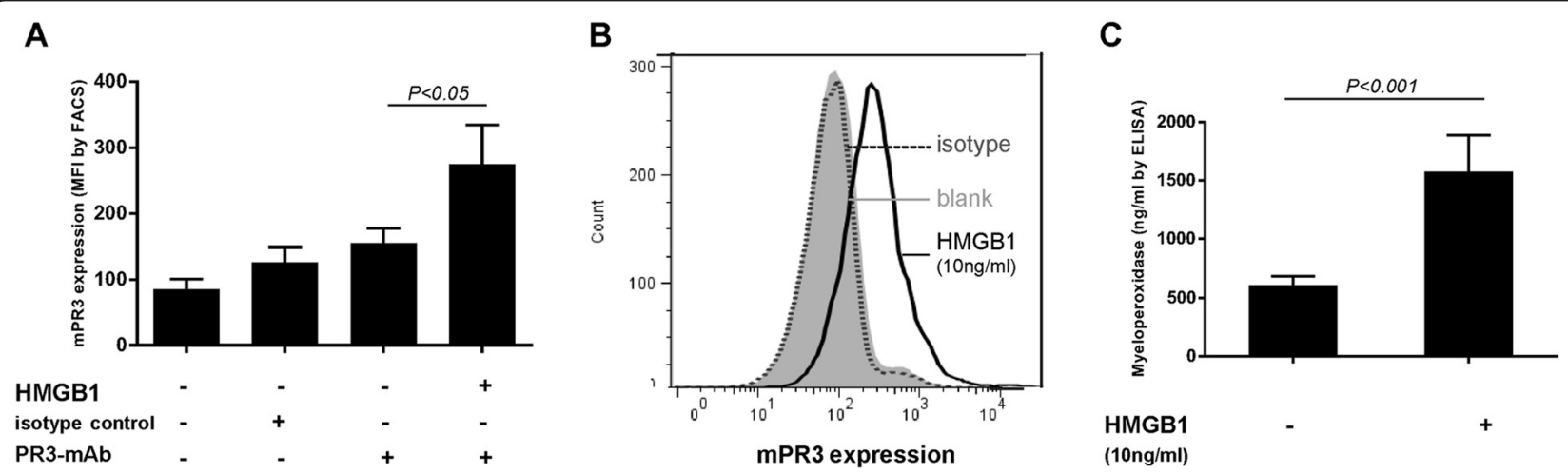

Figure 3 ANCA antigens translocation enhanced by incubation of HMGB1. HMGB1 increased expression of mPR3 on neutrophils ( $\mathrm{A}$ ) and concentration of MPO in the neutrophils culture supernatant (C). (B) was a representative histogram of effects of HMGB1 on translocation of PR3. Bars represent mean \pm standard deviation (SD) of repeated measurements on neutrophils of eight independent experiments and donors. ANCA, antineutrophil cytoplasmic antibody; HMGB1, high mobility group box-1; MPO, myeloperoxidase; PR3, proteinase 3. 
A

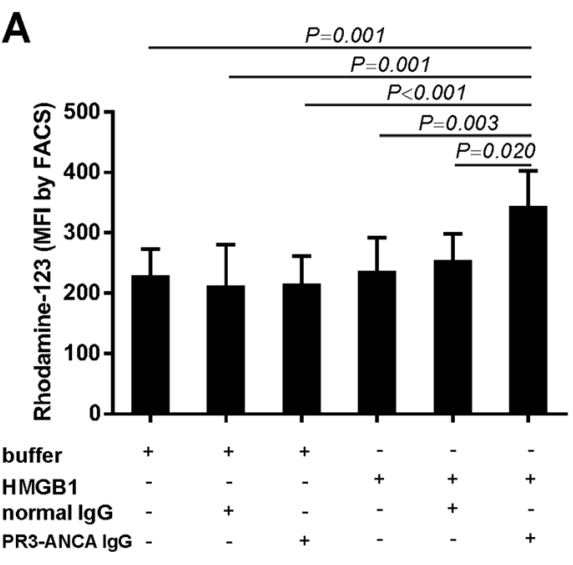

C

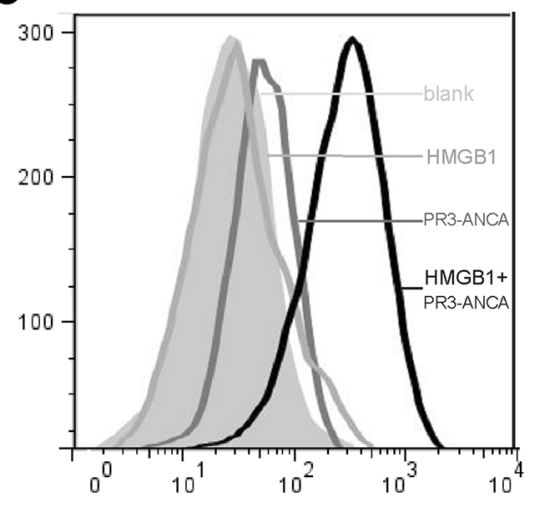

E

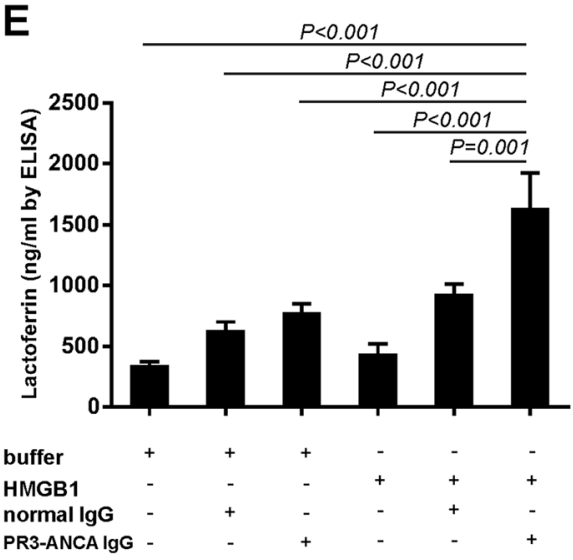

B

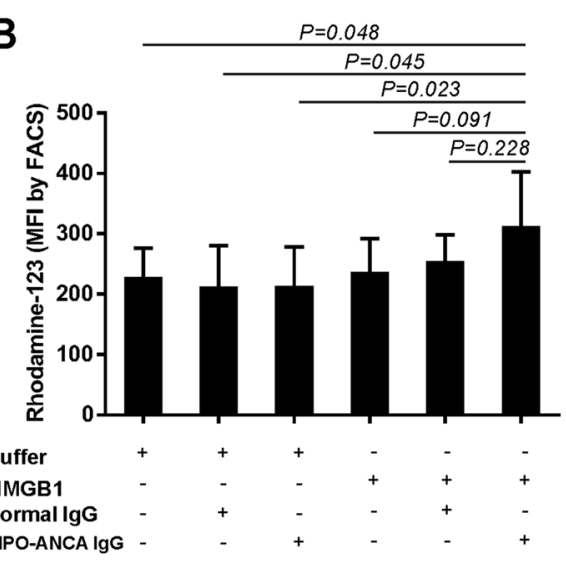

D

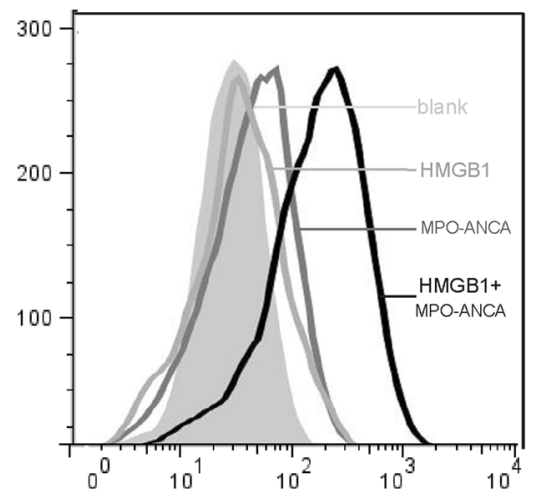

$\mathbf{F}$

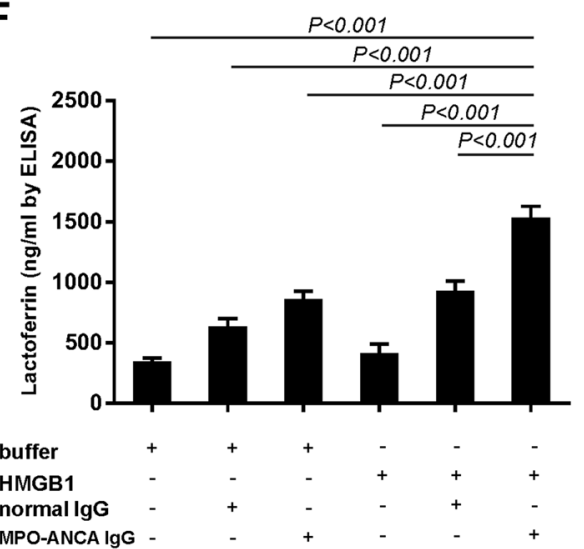

Figure 4 Neutrophil respiratory burst and granulation induced by patient-derived PR3-ANCA-positive IgG or MPO-ANCA-positive IgG in HMGB1-primed neutrophils. Neutrophil respiratory burst induced by patient-derived PR3-ANCA-positive lgG (A) or MPO-ANCA-positive lgG (B) was measured by conversion of dihydrorhodamine to rhodamine-123 in HMGB1-primed cells. (C and D) were representative histograms showing that PR3-ANCA-positive IgG and MPO-ANCA-positive IgG induced respiratory burst in HMGB1-primed neutrophils. Neutrophil granulation induced by patient-derived PR3-ANCA-positive lgG (E) or MPO-ANCA-positive IgG (F) was measured. Bars represent mean \pm standard deviation (SD) of repeated measurements on neutrophils of 8 independent experiments and donors. All statistical differences between groups were shown in the Table S1 in Additional file 3. ANCA, antineutrophil cytoplasmic antibody; HMGB1, high mobility group box-1; IgG, immunoglobulin G; MPO, myeloperoxidase; PR3, proteinase 3.

ANCA-positive $\operatorname{IgG}(345.77 \pm 68.89 \mathrm{ng} / \mathrm{ml}$ vs. $1,639.88 \pm$ $703.15 \mathrm{ng} / \mathrm{ml}, P<0.001)$ or MPO-ANCA- positive IgG $(345.77 \pm 68.89 \mathrm{ng} / \mathrm{ml}$ vs. $1,535.70 \pm 230.59 \mathrm{ng} / \mathrm{ml}$,
$P<0.001)$, respectively. Levels of degranulation were also increased in neutrophils incubated with ANCA-IgG alone, normal IgG alone or HMGB1 plus normal IgG to 
some degree. However, compared with the above neutrophils, the lactoferrin concentration still increased significantly in the supernatant of HMGB1-primed neutrophils further induced by PR3-ANCA-positive IgG or MPOANCA-positive IgG $(P<0.001)$. There was no difference between neutrophils incubated with normal IgG alone and HMGB1 plus normal IgG (Figure 4E and F).

\section{ANCA antigens translocation, ANCA-induced respiratory burst and degranulation in HMGB1-primed neutrophils were TLR4- and RAGE-dependent}

Result of a cytotoxicity assay showed that neutrophils first incubated with anti-TLR2 at $5 \mu \mathrm{g} / \mathrm{ml}$, anti-TLR4 at $5 \mu \mathrm{g} / \mathrm{ml}$, RAGE-Fc at $5 \mu \mathrm{M}, \mathrm{MyD} 88$ inhibitor at $20 \mu \mathrm{M}$ or NF- $\mathrm{KB}$ inhibitor at $20 \mu \mathrm{M}$ for $1 \mathrm{~h}$ on ice had same viability as those with buffer control for $1 \mathrm{~h}$ on ice (Figure 2A).

Using flow cytometry, we showed that parallel experiments blocking TLR4 and RAGE resulted in a significant decrease in HMGB1-induced translocation of mPR3. mPR3 expression decreased from $236.15 \pm 24.79$ in HMGB1-primed neutrophils to $159.54 \pm 22.96$ by preincubating with anti-TLR4 antibody $(P<0.001)$ or $173.28 \pm 29.78$ by pre-incubating with RAGE antagonist $(P<0.001)$, while no significant decrease in neutrophils pre-incubating with anti-TLR2 antibody $(236.15 \pm 24.79$ vs. $217.25 \pm 26.53, P=0.198$ ) (Figure $5 \mathrm{~A}$ ). MPO concentration decreased from $864.65 \pm 405.22 \mathrm{ng} / \mathrm{ml}$ in the supernatant of HMGB1-primed neutrophils to $421.02 \pm$ $89.64 \mathrm{ng} / \mathrm{ml}$ by pre-incubating with anti-TLR4 antibody $(P=0.001)$ or $457.73 \pm 146.74 \mathrm{ng} / \mathrm{ml}$ by pre-incubating with RAGE antagonist $(P=0.003$, respectively), while no significant decrease was found in neutrophils pre-incubating with anti-TLR2 antibody $(864.65 \pm 405.22 \mathrm{ng} / \mathrm{ml}$ vs. $709.77 \pm$ $287.92 \mathrm{ng} / \mathrm{ml}, P=0.259$ ) (Figure $5 \mathrm{~B}$ ).

Blocking TLR4 and RAGE rather than TLR2 also decreased oxygen radical production and lactoferrin release in HMGB1-primed neutrophils induced by ANCApositive IgG from AAV patients. In HMGB1-primed neutrophils, subsequently activating with PR3-ANCApositive IgG, the MFI value was $356.23 \pm 33.21$, which decreased to $286.48 \pm 51.43$ upon pre-incubating with anti-TLR4 antibody $(P=0.007)$, or $285.92 \pm 22.80$ by preincubating with RAGE antagonist $(P=0.007)$, while no significant decrease in neutrophils pre-incubating with anti-TLR2 antibody (356.23 \pm 33.21 vs. $310.53 \pm 52.80$, $P=0.078$ ) (Figure 5C). For MPO-ANCA-positive IgG, the MFI value was $343.08 \pm 61.08$, which decreased to $259.91 \pm 25.66$ by pre-incubating with anti-TLR4 antibody $(P=0.002)$ or $246.80 \pm 12.30$ by pre-incubating with RAGE antagonist ( $P=0.001$, respectively), while no significant decrease in neutrophils pre-incubating with anti-TLR2 antibody (343.08 \pm 61.08 vs. $296.58 \pm 38.42$, $P=0.053$ ) (Figure 5D). The lactoferrin concentration in the supernatant of HMGB1-primed neutrophils induced by PR3-ANCA-positive IgG decreased from 2,033.75 \pm $791.81 \mathrm{ng} / \mathrm{ml}$ to $1,227.35 \pm 400.57 \mathrm{ng} / \mathrm{ml}$ by preincubating with anti-TLR4 antibody $(P=0.005)$, or to $956.94 \pm 394.23$ by pre-incubating with RAGE antagonist $(P<0.001)$, while no significant decrease in neutrophils pre-incubating with anti-TLR2 antibody $(2,033.75 \pm$ $791.81 \mathrm{ng} / \mathrm{ml}$ vs. $1,620.53 \pm 698.98, P=0.130$ ) (Figure $5 \mathrm{E}$ ). For MPO-ANCA-positive IgG, the lactoferrin concentration in the supernatant decreased from 1,242.20 \pm $377.44 \mathrm{ng} / \mathrm{ml}$ in the supernatant of HMGB1-primed neutrophils induced by MPO-ANCA-positive IgG to $810.69 \pm$ $278.61 \mathrm{ng} / \mathrm{ml}$ by pre-incubating with anti-TLR4 antibody $(P=0.003)$, or $754.56 \pm 249.61 \mathrm{ng} / \mathrm{ml}$ by pre-incubating with RAGE antagonist $(P=0.001)$, while no significant decrease in neutrophils pre-incubating with anti-TLR2 antibody $(1,242.20 \pm 377.44 \mathrm{ng} / \mathrm{ml}$ vs. $1030.63 \pm 339.24 \mathrm{ng} / \mathrm{ml}$, $P=0.125$ ) (Figure 5F).

Combined blockade of TLR4 and RAGE further decreased ANCA antigens translocation, ANCA-induced respiratory burst and degranulation in HMGB1-primed neutrophils to a certain degree. However, the effects were not completely overlaid (Figure 5).

To further confirm the receptors through which HMGB1 exerts its effects, we used TLR2-/- and TLR4-/mice [30] and a neutrophil-like HL-60 cell line transfected by TLR2, TLR4 or RAGE siRNA to interfere the expression of corresponding receptors at genetic level to validate our findings. The results were in line with our data of human neutrophils with inhibitors and blocking antibodies to block the activity of corresponding receptors. For detailed information, see Additional file 4, Figure S2 in Additional file 5, Figure S3 in Additional file 6 and Figure $\mathrm{S} 4$ in Additional file 7.

\section{Enhanced activation of MyD88 and NF-KB contributed to the priming effect of $\mathrm{HMGB} 1$ on neutrophils}

Since ANCA antigens translocation, ANCA-induced respiratory burst and degranulation in HMGB1-primed neutrophils were TLR4- and RAGE-dependent, we next investigated whether HMGB1-primed neutrophils were dependent on activation of MyD88/NF-kB pathways. We analyzed the effect of HMGB1 priming as well as the effect of the subsequent ANCA-positive IgG stimulation.

Western blot analysis was performed to study the expression of MyD88 and phosphorylated NF- $\mathrm{kB}$ p65. Figure 6 showed a representative Western blot analysis of MyD88 and phosphorylated NF- $\mathrm{kB}$ p65 and the corresponding Western blot analysis. We observed significantly increased MyD88 and phosphorylated NF- $\mathrm{kB}$ p65 in neutrophils incubated with HMGB1 or HMGB1 plus ANCA-positive IgG, which then decreased in certain groups by preincubating with anti-TLR4 antibody or RAGE antagonist. However, there are no significant change of the expression 
A



C

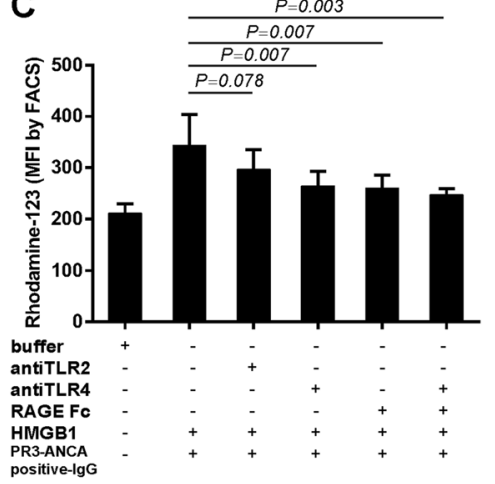

E
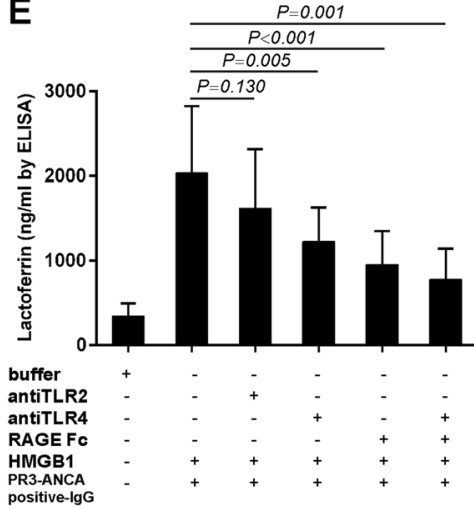

B

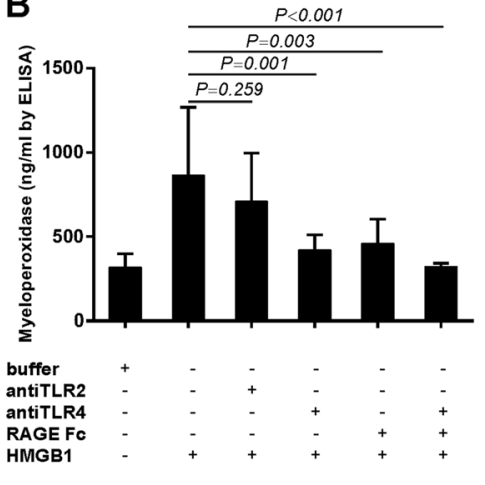

D

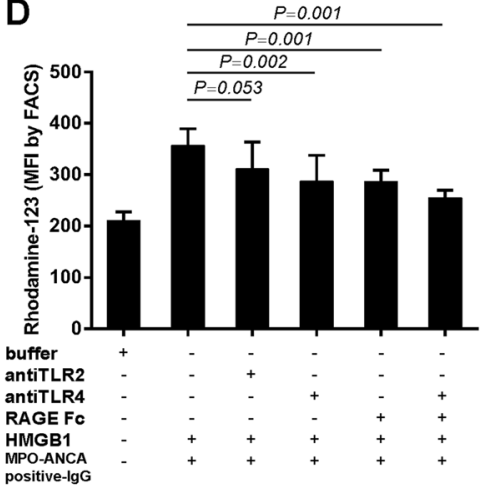

$\mathbf{F}$
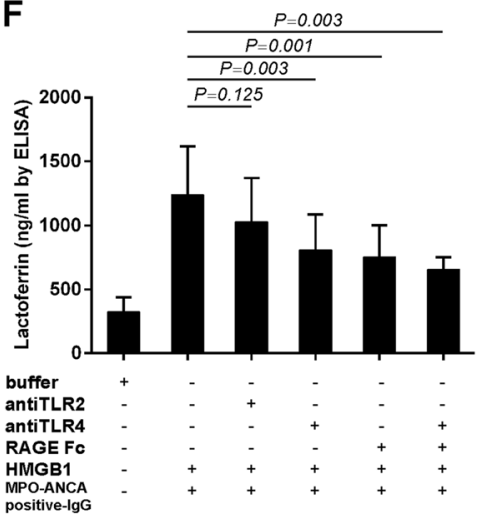

Figure 5 Blockage of TLR4 and RAGE rather than TLR2 decreased ANCA antigens translocation, ANCA-induced respiratory burst and degranulation in HMGB1-primed neutrophils. Blockage of TLR4 and RAGE rather than TLR2 decreased expression of mPR3 on HMGB1-primed neutrophils (A) and concentration of MPO in the neutrophils culture supernatant (B). Blockage of TLR4 and RAGE rather than TLR2 decreased neutrophil respiratory burst induced by patient-derived PR3-ANCA-positive lgG (C) or MPO-ANCA-positive IgG (D) in HMGB1-primed cells. Blockage of TLR4 and RAGE rather than TLR2 decreased neutrophil degranulation induced by patient-derived PR3-ANCA-positive IgG (E) or MPO-ANCA-positive lgG (F) in HMGB1-primed cells. Bars represent mean \pm standard deviation (SD) of repeated measurements on neutrophils of 8 independent experiments and donors. All statistical differences between groups were shown in the Table S2 in Additional file 3. ANCA, antineutrophil cytoplasmic antibody; HMGB1, high mobility group box-1; lgG, immunoglobulin G; MPO, myeloperoxidase; PR3, proteinase 3; RAGE, receptor for advanced glycation end products; TLR, Toll-like receptor.

of MyD88 and phosphorylated NF-kB p65 in the group pre-incubated by anti-TLR2 antibody.

Compared with the neutrophils merely primed by HMGB1 and subsequently stimulated by ANCApositive IgG, pre-incubation of neutrophils with inhibitors of MyD88 and NF- $\mathrm{kB}$ decreased ANCA antigens translocation, ANCA-induced respiratory burst and degranulation in HMGB1-primed neutrophils. mPR3 expression decreased by pre-incubating with inhibitors of MyD88 and NF-kB (251.25 \pm 56.38 vs. $153.75 \pm 62.61, P=$ $0.003 ; 251.25 \pm 56.38$ vs. $97.38 \pm 13.68, P<0.001$, respectively) (Figure 7A). Similarly, MPO concentration in 


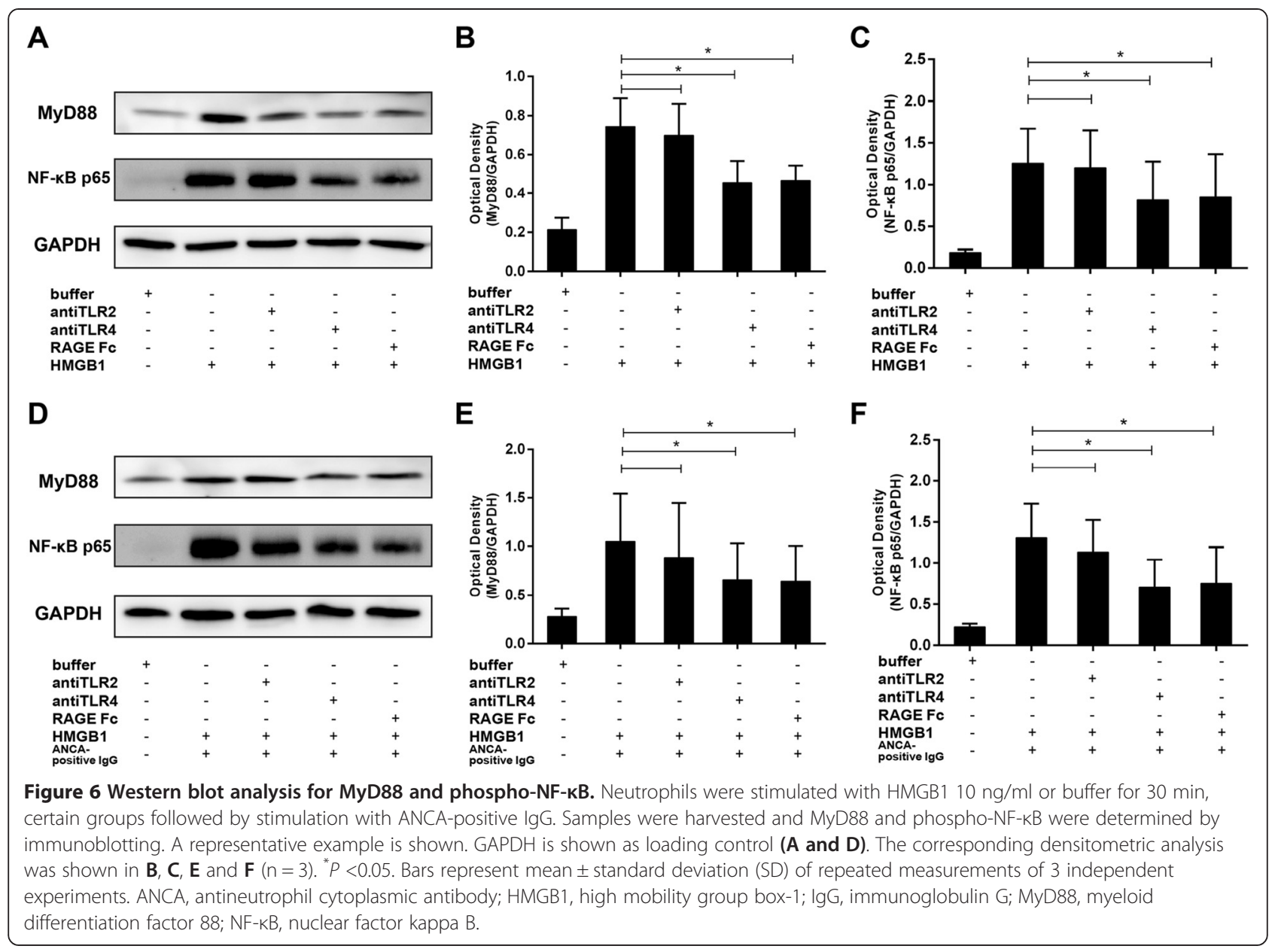

the supernatant of neutrophils decreased by pre-incubating with inhibitors of MyD88 and NF- $\mathrm{BB}(2,032.47 \pm$ $503.41 \mathrm{ng} / \mathrm{ml}$ vs. $1,207.38 \pm 572.31 \mathrm{ng} / \mathrm{ml}, P=0.019$; $2,032.47 \pm 503.41 \mathrm{ng} / \mathrm{ml}$ vs. $1,035.93 \pm 304.65 \mathrm{ng} / \mathrm{ml}$, $P<0.001$, respectively) (Figure $7 \mathrm{~B}$ ).

Blocking MyD88 or NF-kB also decreased oxygen radical production in HMGB1-primed neutrophils induced by ANCA-positive IgG from AAV patients (for PR3ANCA-positive IgG, $302.40 \pm 31.72$ vs. $216.54 \pm 32.63, P=$ $0.019 ; 302.40 \pm 31.72$ vs. $194.33 \pm 49.07, P=0.005$, respectively; for MPO-ANCA-positive IgG, $285.24 \pm 40.39$ vs. $212.88 \pm 18.61, P=0.024 ; 285.24 \pm 40.39$ vs. $182.33 \pm 27.46$, $P=0.003$, respectively) (Figure $7 \mathrm{C}$ and $\mathrm{D}$ ).

Blocking MyD88 or NF-kB had the similar effect on degranulation in HMGB1-primed neutrophils induced by ANCA-positive IgG. The lactoferrin concentration in the supernatant decreased significantly (for PR3-ANCApositive IgG, $1,633.21 \pm 504.05 \mathrm{ng} / \mathrm{ml}$ vs. $920.55 \pm$ $268.33 \mathrm{ng} / \mathrm{ml}, \quad P=0.02 ; 1,633.21 \pm 504.05 \mathrm{ng} / \mathrm{ml} \quad$ vs. $624.13 \pm 444.27 \mathrm{ng} / \mathrm{ml}, P=0.002$, respectively; for MPOANCA-positive IgG, 1,350.15 $\pm 447.05 \mathrm{ng} / \mathrm{ml}$ vs. $832.80 \pm$ $295.00 \mathrm{ng} / \mathrm{ml}, \quad P=0.045 ; 1,350.15 \pm 447.05 \mathrm{ng} / \mathrm{ml}$ vs.
$460.97 \pm 119.93 \mathrm{ng} / \mathrm{ml}, P=0.002$, respectively) (Figure $7 \mathrm{E}$ and $\mathrm{F}$ ). These data suggested important roles for the TLR4/MyD88/NF-kB pathway and RAGE/MyD88/NF-кB pathway in HMGB1-mediated priming of neutrophils.

\section{Discussion}

As an essential DAMP molecule, HMGB1 is released by stimulated neutrophils, macrophages and monocytes, and then regulates cytokine expression and promotes inflammatory cell recruitment [31,32]. Furthermore, elevated levels of HMGB1 have been implicated in the pathogenesis of a broad range of acute and chronic inflammatory conditions in sepsis, cancer, systemic lupus erythematosus and rheumatoid arthritis [33-37]. Recently, we observed circulating HMGB1 levels are associated with the disease activity of AAV [14], which was in line with and further extended the earlier related findings [38-40], although it remains controversial in studies by de Souza et al. [41,42]. Whether HMGB1 participated in the pathogenesis of AAV, and then the underlying mechanism was not fully clear yet. 
A

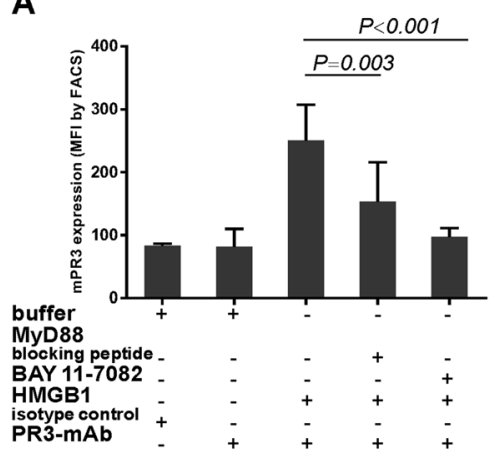

C

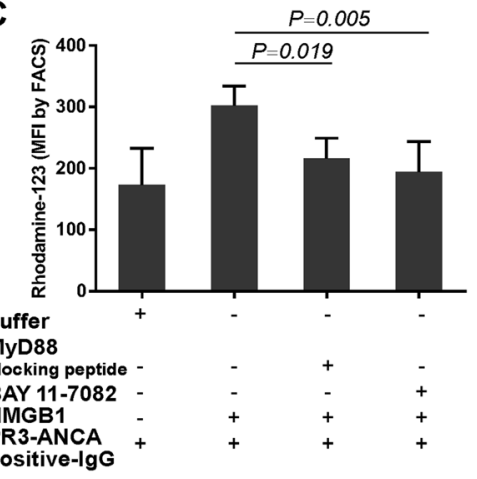

E

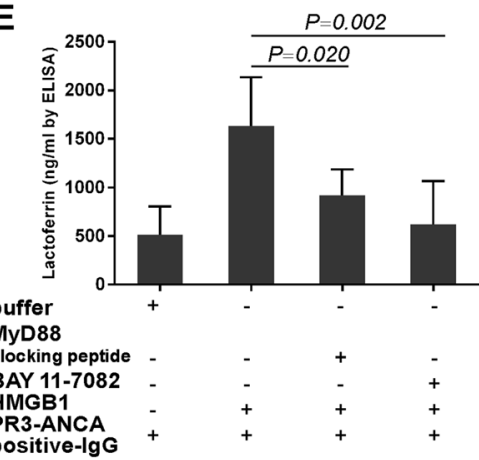

B

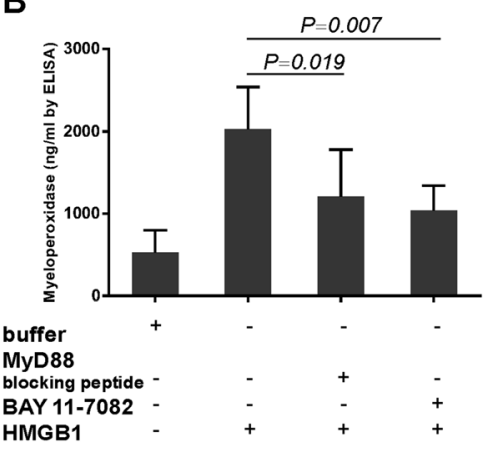

D

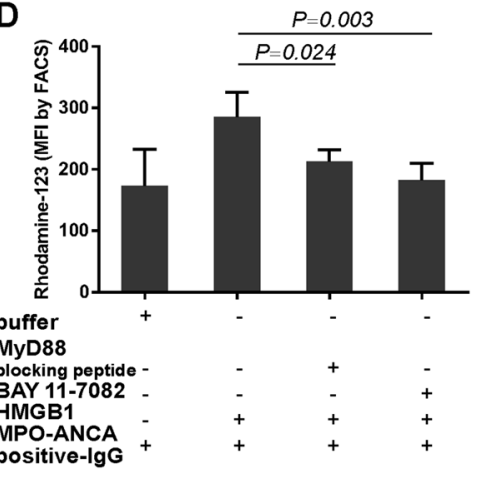

$\mathbf{F}$

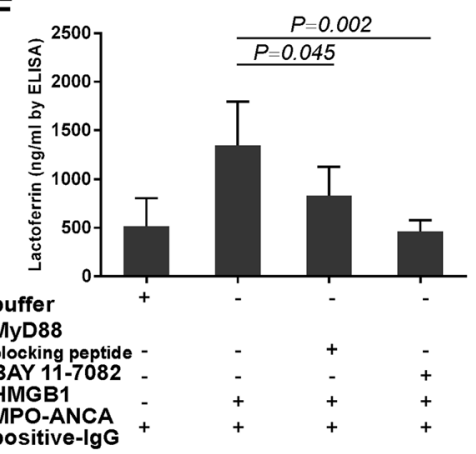

Figure 7 MyD88 and NF-KB inhibitors decreased ANCA antigens translocation, ANCA-induced respiratory burst and degranulation in HMGB1-primed neutrophils. Inhibition of MyD88 and NF-KB decreased expression of mPR3 on HMGB1-primed neutrophils (A) and concentration of MPO in the neutrophils culture supernatant (B). Inhibition of MyD88 and NF-KB decreased neutrophil respiratory burst induced by patient-derived PR3-ANCA-positive lgG (C) or MPO-ANCA-positive lgG (D) in HMGB1-primed cells. Inhibition of MyD88 and NF-KB decreased neutrophil degranulation induced by patient-derived PR3-ANCA-positive lgG (E) or MPO-ANCA-positive lgG (F) in HMGB1-primed cells. Bars represent mean \pm standard deviation (SD) of repeated measurements on neutrophils of five independent experiments and donors. All statistical differences between groups were shown in the Table $\mathbf{S 3}$ in Additional file 3.

ANCA-induced neutrophils respiratory burst and degranulation was crucial in the development of AAV, with assistance from a variety of proinflammatory factors by priming the neutrophils to express more ANCA target antigens [2-4]. Taking the multiple effects of HMGB1 on neutrophils into consideration, we carried out the investigation to figure out the role of HMGB1 in ANCAinduced neutrophil activation. The results showed that HMGB1 is able to prime neutrophils by increasing ANCA antigens translocation, and the primed neutrophils could be further activated by ANCA-positive IgG from AAV patients, resulting in the respiratory burst and degranulation.

According to our previous studies [21], the increase in membrane-bound MPO expression were much lower than that in mPR3 expression after incubation with priming factors, which was in line with some other studies $[6,23]$. Therefore, in the current study, we measured the concentrations of secreted MPO in the supernatant of HMGB1-primed neutrophils using specific ELISA kit. However, it was inconsistent with Maugeri's study [43], 
in which neutrophils express more membrane-bound MPO after stimulated by HMGB1. Such discrepancy might be attributed to the difference of incubation time. In Maugeri's study, neutrophils were incubated with HMGB1 for 5 minutes, which was much shorter than that in our current study (30 minutes). As reported by Witko-Sarsat et al. [22], MPO was mainly released into the extracellular medium and PR3 was released in minute amounts into the extracellular medium. It was possible that the membrane-bound MPO had been released into the extracellular medium when we measured the neutrophils. It is also notable that, compared with neutrophils incubated with HMGB1 alone, the MPO concentration increased significantly in the supernatant of HMGB1primed neutrophils further activated by ANCA-positive IgG (see Figure S5 in Additional file 8). It indicated the above process of MPO releasing from neutrophils incubated with HMGB1 alone is a priming process, rather than an actual complete degranulation with granule depletion.

HMGB1 exerts its proinflammatory effects through various receptors, among which, RAGE, TLR2 and TLR4 on the neutrophils surface may be the representative ones [11-13]. TLR4 transmits signals via MyD88-dependent and MyD88-independent pathways, and the former signaling pathway, which might finally activate NF-kB, was shown to be responsible for proinflammatory cytokine expression $[27,44,45]$. RAGE engagement by multiple ligands activates various signaling pathways, that is, through the adaptors Dia-1, TIR domain-containing adaptor protein (TIRAP)MyD88 and/or as yet unidentified adaptors, which in turn activate signaling molecules impinging on transcription factors, such as NF-кB. Besides, activation of RAGE induces generation of oxygen radicals by a yet unknown mechanism $[28,46]$. In the current study, ANCA antigens translocation, ANCA-induced respiratory burst and degranulation in HMGB1-primed neutrophils were found to be TLR4- and RAGE-dependent. Moreover, the signaling pathways of both TLR4 and RAGE might be MyD88-dependent and finally activate NF- $\mathrm{kB}$, causing its phosphorylation. To some extent, the inhibitory effect by blocking receptors and signaling molecules on ANCA-induced activation of HMGB1primed neutrophils might be through inhibition of ANCA target antigens translocation. We also found combined blockade of TLR4 and RAGE could further decrease the effects of HMGB1 on neutrophils. However, these effects were not completely overlaid. We speculated that there are some crosstalks between these two receptors and they may share partial pathways involved in this process. What is more, the effects of HMGB1 exerts on neutrophils may be dose-dependent, mainly through the TLR4- and RAGEMyD88/NF-kB pathway. For example, a lower concentration of HMGB1 at $5 \mathrm{ng} / \mathrm{ml}$, which was comparable to the circulating HMGB1 level in AAV patients at remission stage [14], still depended on the same pathways to exert the effects on neutrophils (see Figure S6 in Additional file 9).

\section{Conclusions}

Our data demonstrated that HMGB1 is able to prime neutrophils by increasing ANCA antigens translocation, and the primed neutrophils could be further induced by ANCA, resulting in the respiratory burst and degranulation. The process is TLR4- and RAGE-dependent through the MyD88/NF-kB pathway. It suggested that blockade of HMGB1 might limit inflammatory damage caused by ANCA-activated neutrophils, and figuring out the signaling pathways in the process might provide potential clues for intervention strategies.

\section{Additional files}

Additional file 1: To evaluate the influence of contaminating platelet in neutrophils isolated from different anticoagulant tubes.

Additional file 2: Figure S1. The platelet contamination rates and membrane-bound PR3 expression on these neutrophils after priming in neutrophils isolated from blood in sodium citrate tube, EDTA tube and heparin tube. The platelet contamination rates in neutrophils isolated from blood in sodium citrate tube (A), EDTA tube (B) and heparin tube (C). The membrane-bound PR3 expression on these neutrophils after priming in neutrophils isolated from blood in sodium citrate tube (D), EDTA tube (E) and heparin tube (F).

Additional file 3: Table S1. Statistical differences between groups in Figure 4. Table S2. Statistical differences between groups in Figure 5. Table S3. Statistical differences between groups in Figure 7.

Additional file 4: To confirm the receptors of HMGB1 by gene knockout animals and a neutrophil-like $\mathrm{HL}-60$ cell line transfected with small interfering RNAs.

Additional file 5: Figure S2. Release of MPO by HMGB1-primed murine neutrophils from TLR2-/- and TLR4-/- mice. HMGB1 increased concentration of MPO in the culture supernatant of neutrophils from TLR2 - - - mice as wild-type mice (A). HMGB1 could not increase concentration of MPO in the culture supernatant of neutrophils from TLR4 -/- mice as wild-type mice (B). Bars represent mean \pm SD of repeated measurements on neutrophils of five independent experiments and mice.

Additional file 6: Figure S3. Anti-MPO IgGs-induced respiratory burst in HMGB1-primed murine neutrophils from TLR2-/- and TLR4-/- mice. Murine neutrophil respiratory burst induced by anti-MPO lgGs was measured by conversion of dihydrorhodamine to Rho-123 in HMGB1-primed cells (C, F). A-B and D-E were representative flow cytometry results. The percentage of $\mathrm{Ly} 6 \mathrm{G}+\mathrm{Rho}+$ neutrophils were regarded as level of respiratory burst. Bars represent mean \pm SD of repeated measurements on neutrophils of three independent experiments and mice.

Additional file 7: Figure S4. Expression of membrane-bound PR3 on HMGB1-primed neutrophils-like HL-60 cells and anti-MPO IgGs-induced respiratory burst in HMGB1-primed neutrophils-like HL-60 cells transfected with TLR2, TLR4 or RAGE siRNA. HMGB1 increased expression of membrane-bound PR3 on neutrophil-like HL-60 cells transfected with TLR2, TLR4 or RAGE siRNA (A). Anti-MPO IgGs-induced respiratory burst in HMGB1-primed neutrophil-like HL-60 cells transfected with TLR2, TLR4 or RAGE siRNA (B). Bars represent mean \pm SD of repeated measurements on neutrophils of three independent experiments.

Additional file 8: Figure S5. The MPO concentration in the supernatant of neutrophils under various stimulation. The MPO concentration increased significantly in the supernatant of HMGB1-primed neutrophils further activated by ANCA-positive lgG. 
Additional file 9: Figure S6. Expression of membrane-bound PR3 and anti-MPO IgGs-induced respiratory burst on neutrophils primed by a lower concentration of HMGB1 at $5 \mathrm{ng} / \mathrm{ml}$ with/without blockage of TLR2, TLR4, RAGE, MyD88 or NF-KB. The lower concentration of HMGB1 at $5 \mathrm{ng} / \mathrm{ml}$ still depended on the same pathways to exert the effects on neutrophils.

\section{Abbreviations}

AAV: ANCA-associated vasculitis; ANCA: antineutrophil cytoplasmic antibody; BSA: bovine serum albumin; DAMP: damage-associated molecular pattern; EGPA: eosinophilic granulomatosis with polyangiits; ELISA: enzyme-linked immunosorbent assay; GPA: granulomatosis with polyangiitis; HBSS: Hank's balanced salt solution; HMGB1: high mobility group box-1; IgG: immunoglobulin G; IRAKs: interleukin-1 receptor-associated kinases; LDH: lactate dehydrogenase; MAPKK: mitogen-activated protein kinasekinase; MFI: mean fluorescence intensity; MPA: microscopic polyangiitis; MPO: myeloperoxidase; MyD88: myeloid differentiation factor 88; NF-kB: nuclear factor kappa B; PE: phycoerythrin; PR3: proteinase 3; RAGE: receptor for advanced glycation end products; TBST: Tris-buffered saline with Tween 20; TIRAP: TIR domain-containing adaptor protein; TLR: Toll-like receptor; TNF-a: tumor necrosis factor alpha; TRAF6/IKK: TNF receptor-associated factor 6//kB kinase.

\section{Competing interests}

The authors declare that they have no competing interests.

\section{Authors' contributions}

CW carried out the experiments, analyzed the data and drafted the manuscript. HW participated in carrying out the flow cytometry assays and helped to revise the manuscript. JH participated in the design of the study and helped to revise the manuscript. DYC contributed reagents/materials/ analysis tools and helped to revise the manuscript. MHZ conceived of the study, participated in its design and coordination and helped to draft the manuscript. MC conceived of the study, participated in its design and coordination, helped to draft the manuscript and is responsible for the interpretation of the data. All authors read and approved the final manuscript.

\section{Acknowledgements}

This study is supported by a grant from the Chinese 973 project (No. 2012CB517702), and three grants from the National Natural Science Fund (No. 81425008, No. 81321064 and No. 81300599), and 'National Key Technology Research and Development (R\&D) Program' of the Ministry of Science and Technology of China (No. 2011BAl10B04).

\section{Received: 1 September 2014 Accepted: 25 February 2015}

\section{Published online: 18 March 2015}

\section{References}

1. Jennette JC, Falk RJ, Bacon PA, Basu N, Cid MC, Ferrario F, et al. 2012 revised international chapel hill consensus conference nomenclature of vasculitides. Arthritis Rheum. 2013;65:1-11.

2. Falk RJ, Terrell RS, Charles LA, Jennette JC. Anti-neutrophil cytoplasmic autoantibodies induce neutrophils to degranulate and produce oxygen radicals in vitro. Proc Natl Acad Sci U S A. 1990;87:4115-9.

3. Charles LA, Caldas ML, Falk RJ, Terrell RS, Jennette JC. Antibodies against granule proteins activate neutrophils in vitro. J Leukoc Biol. 1991;50:539-46.

4. Keogan MT, Esnault VL, Green AJ, Lockwood CM, Brown DL. Activation of normal neutrophils by anti-neutrophil cytoplasm antibodies. Clin Exp Immunol. 1992;90:228-34.

5. Mulder AH, Heeringa P, Brouwer E, Limburg PC, Kallenberg CG. Activation of granulocytes by anti-neutrophil cytoplasmic antibodies (ANCA): a Fc gamma RIl-dependent process. Clin Exp Immunol. 1994;98:270-8.

6. Hess C, Sadallah S, Schifferli JA. Induction of neutrophil responsiveness to myeloperoxidase antibodies by their exposure to supernatant of degranulated autologous neutrophils. Blood. 2000;96:2822-7.

7. Xiao H, Heeringa P, Hu P, Liu Z, Zhao M, Aratani Y, et al. Antineutrophil cytoplasmic autoantibodies specific for myeloperoxidase cause glomerulonephritis and vasculitis in mice. J Clin Invest. 2002;110:955-63.
8. Xiao H, Heeringa $P$, Liu Z, Huugen $D$, Hu P, Maeda N, et al. The role of neutrophils in the induction of glomerulonephritis by anti-myeloperoxidase antibodies. Am J Pathol. 2005;167:39-45.

9. Müller S, Scaffidi P, Degryse B, Bonaldi T, Ronfani L, Agresti A, et al. New EMBO members' review: the double life of HMGB1 chromatin protein: architectural factor and extracellular signal. EMBO J. 2001;20:4337-40.

10. Seong SY, Matzinger P. Hydrophobicity: an ancient damage-associated molecular pattern that initiates innate immune responses. Nat Rev Immunol. 2004;4:469-78

11. Kokkola R, Andersson A, Mullins G, Ostberg T, Treutiger CJ, Arnold B, et al. RAGE is the major receptor for the pro-inflammatory activity of HMGB1 in rodent macrophages. Scand J Immunol. 2005;61:1-9.

12. Park JS, Svetkauskaite D, He Q, Kim JY, Strassheim D, Ishizaka A, et al. Involvement of toll-like receptors 2 and 4 in the cellular activation by high mobility group box 1 protein. J Biol Chem. 2004;279:7370-7.

13. Bianchi ME. HMGB1 loves company. J Leukoc Biol. 2009;86:573-6.

14. Wang C, Gou SJ, Chang DY, Yu F, Zhao MH, Chen M. Association of circulating level of high mobility group Box 1 with disease Activity in antineutrophil cytoplasmic autoantibody-associated vasculitis. Arthritis Care Res. 2013;65:1828-34.

15. Fan J, Li Y, Levy RM, Fan JJ, Hackam DJ, Vodovotz Y, et al. Hemorrhagic shock induces $\mathrm{NAD}(\mathrm{P}) \mathrm{H}$ oxidase activation in neutrophils: role of HMGB1TLR4 signaling. J Immunol. 2007;178:6573-80.

16. Berthelot F, Fattoum L, Casulli S, Gozlan J, Maréchal V, Elbim C. The effect of HMGB1, a damage-associated molecular pattern molecule, on polymorphonuclear neutrophil migration depends on its concentration. J Innate Immun. 2012:4:41-58.

17. Yang H, Antoine DJ, Andersson U, Tracey KJ. The many faces of HMGB1: molecular structure-functional activity in inflammation, apoptosis, and chemotaxis. J Leukoc Biol. 2013;93:865-73.

18. Pisetsky DS. The translocation of nuclear molecules during inflammation and cell death. Antioxid Redox Signal. 2013;20:1117-25.

19. Schreiber A, Rolle S, Peripelittchenko L, Rademann J, Schneider W, Luft FC, et al. Phosphoinositol 3-kinase-gamma mediates antineutrophil cytoplasmic autoantibody-induced glomerulonephritis. Kidney Int. 2010;77:118-28.

20. Choi M, Rolle S, Rane M, Haller H, Luft FC, Kettritz R. Extracellular signalregulated kinase inhibition by statins inhibits neutrophil activation by ANCA. Kidney Int. 2003:63:96-106

21. Hao J, Meng LQ, Xu PC, Chen M, Zhao MH. P38MAPK, ERK and PI3K signaling pathways are involved in C5a-primed neutrophils for ANCA-mediated activation. PLoS One. 2012;7:e38317.

22. Witko-Sarsat V, Cramer EM, Hieblot C, Guichard J, Nusbaum P, Lopez S, et al. Presence of proteinase 3 in secretory vesicles: evidence of a novel, highly mobilizable intracellular pool distinct from azurophil granules. Blood. 1999:94:2487-96.

23. Reumaux D, Vossebeld PJ, Roos D, Verhoeven AJ. Effect of tumor necrosis factor-induced integrin activation on Fc gamma receptor II-mediated signal transduction: relevance for activation of neutrophils by anti-proteinase 3 or anti-myeloperoxidase antibodies. Blood. 1995;86:3189-95.

24. Kauskot A, Adam F, Mazharian A, Ajzenberg N, Berrou E, Bonnefoy A, et al. Involvement of the mitogen-activated protein kinase c-Jun $\mathrm{NH}$ 2-terminal kinase 1 in thrombus formation. J Biol Chem. 2007;282:31990-9.

25. Talor MV, Stone JH, Stebbing J, Barin J, Rose NR, Burek CL. Antibodies to selected minor target antigens in patients with anti-neutrophil cytoplasmic antibodies (ANCA). Clin Exp Immunol. 2007;150:42-8.

26. Rodriguez-Franco DA, Vazquez-Moreno L, Ramos-Clamont MG. Antimicrobial mechanisms and potential clinical application of lactoferrin. Rev Latinoam Microbiol. 2005:47:102-11.

27. Chang ZL. Important aspects of Toll-like receptors, ligands and their signaling pathways. Inflamm Res. 2010;59:791-808.

28. Huttunen HJ, Fages C, Rauvala H. Receptor for advanced glycation end products (RAGE)-mediated neurite outgrowth and activation of NF-kappaB require the cytoplasmic domain of the receptor but different downstream signaling pathways. J Biol Chem. 1999;274:19919-24.

29. Ritis K, Doumas M, Mastellos D, Micheli A, Giaglis S, Magotti P, et al. A novel C5a receptor-tissue factor cross-talk in neutrophils links innate immunity to coagulation pathways. J Immunol. 2006;177:4794-802.

30. Maugeri N, Campana L, Gavina M, Covino C, De Metrio M, Panciroli C, et al, Activated platelets present high mobility group box 1 to neutrophils, inducing autophagy and promoting the extrusion of neutrophil extracellular traps. J Thromb Haemost. 2014;12:2074-88. 
31. Scaffidi P, Misteli T, Bianchi ME. Release of chromatin protein HMGB1 by necrotic cells triggers inflammation. Nature. 2002;418:191-5.

32. Andersson U, Wang H, Palmblad K, Aveberger AC, Bloom O, ErlandssonHarris $\mathrm{H}$, et al. High mobility group 1 protein (HMG-1) stimulates proinflammatory cytokine synthesis in human monocytes. J Exp Med. 2000;192:565-70.

33. Wang $H$, Yang $H$, Tracey $\mathrm{KJ}$. Extracellular role of HMGB1 in inflammation and sepsis. J Int Med. 2004;255:320-31.

34. Ellerman JE, Brown CK, de Vera M, Zeh HJ, Billiar T, Rubartelli A, et al. Masquerader: high mobility group box-1 and cancer. Clin Cancer Res. 2007;13:2836-48.

35. Taniguchi N, Kawahara K, Yone K, Hashiguchi T, Yamakuchi M, Goto M, et al. High mobility group box chromosomal protein 1 plays a role in the pathogenesis of rheumatoid arthritis as a novel cytokine. Arthritis Rheum. 2003;48:971-81.

36. Jiang W, Pisetsky DS. Expression of high mobility group protein 1 in the sera of patients and mice with systemic lupus erythematosus. Ann Rheum Dis. 2008;67:727-8.

37. Urbonaviciute V, Fürnrohr BG, Meister S, Munoz L, Heyder P, De Marchis F, et al. Induction of inflammatory and immune responses by HMGB1-nucleosome complexes: implications for the pathogenesis of SLE. J Exp Med. 2008;205:3007-18.

38. Bruchfeld A, Wendt M, Bratt J, Qureshi AR, Chavan S, Tracey KJ, et al. Highmobility group box-1 protein (HMGB1) is increased in antineutrophilic cytoplasmatic antibody (ANCA)-associated vasculitis with renal manifestations. Mol Med. 2011;17:29-35

39. Wibisono D, Csernok E, Lamprecht P, Holle JU, Gross WL, Moosig F. Serum HMGB1 levels are increased in active Wegener's granulomatosis and differentiate between active forms of ANCA-associated vasculitis. Ann Rheum Dis. 2010;69:1888-9.

40. Henes FO, Chen Y, Bley TA, Fabel M, Both M, Herrmann K, et al. Correlation of serum level of high mobility group box 1 with the burden of granulomatous inflammation in granulomatosis with polyangiitis (Wegener's). Ann Rheum Dis. 2011;70:1926-9.

41. de Souza AW, Bijzet J, Limburg PC, Stegeman CA, Bijl M, Kallenberg CG. Is serum HMGB1 a biomarker in ANCA-associated vasculitis? Arthritis Res Ther. 2013;15:R104.

42. de Souza AW, Abdulahad WH, Sosicka P, Bijzet J, Limburg PC, Stegeman CA et al. Are urinary levels of high mobility group box 1 markers of active nephritis in anti-neutrophil cytoplasmic antibody-associated vasculitis? Clin Exp Immunol. 2014;178:270-8.

43. Maugeri N, Rovere-Querini P, Baldini M, Baldissera E, Sabbadini MG, Bianchi $M E$, et al. Oxidative stress elicits platelet/leukocyte inflammatory interactions via HMGB1: a candidate for microvessel injury in sytemic sclerosis. Antioxid Redox Signal. 2014:20:1060-74.

44. Ahmed A, Redmond HP, Wang JH. Links between Toll-like receptor 4 and breast cancer. Oncoimmunology. 2013;2:e22945.

45. Lu YC, Yeh WC, Ohashi PS. LPS/TLR4 signal transduction pathway. Cytokine 2008;42:145-51.

46. Sorci G, Riuzzi F, Giambanco I, Donato R. RAGE in tissue homeostasis, repair and regeneration. Biochim Biophys Acta. 2013;1833:101-9.

\section{Submit your next manuscript to BioMed Central and take full advantage of:}

- Convenient online submission

- Thorough peer review

- No space constraints or color figure charges

- Immediate publication on acceptance

- Inclusion in PubMed, CAS, Scopus and Google Scholar

- Research which is freely available for redistribution 